\title{
FUNDAMENTOS DE FRAGILIDAD SÍSMICA DE ESTRUCTURAS CON MUROS CORTANTES DE HORMIGÓN ARMADO: ESTADO DEL ARTE
}

\section{FUNDAMENTALS OF SEISMIC FRAGILITY OF REINFORCED CONCRETE SHEAR WALL STRUCTURES: STATE-OF-THE-ART}

\author{
Ana Gabriela Haro \\ Departamento de Ciencias de la Tierra y la Construcción \\ Universidad de las Fuerzas Armadas ESPE, 171-5231B, \\ Sangolquí-Ecuador \\ agharo@espe.edu.ec \\ North Carolina State University, Raleigh, NC 27695, USA \\ agharo@ncsu.edu
}

\begin{abstract}
RESUMEN
Muros cortantes o muros estructurales de hormigón armado son considerados como sistemas laterales resistentes efectivos en países localizados en regiones susceptibles a terremotos. Sin embargo, se ha detectado la necesidad de procesos confiables para identificar el comportamiento de estos elementos estructurales a fin de prevenir pérdidas no esperadas. Este hecho ha sido corroborado a partir de reportes de daño después de la ocurrencia de sismos fuertes recientes. En la práctica, curvas de fragilidad son usadas para análisis de riesgo sísmico porque tienen la capacidad de cuantificar la probabilidad cumulativa de falla relacionada con algún parámetro de diseño de ingeniería. Este artículo detalla los fundamentos del estado del arte asociado con la fragilidad sísmica de casos seleccionados de estructuras con muros cortantes de hormigón armado con el objetivo de promover estudios más avanzados y necesarios en la región.
\end{abstract}

Palabras clave: fragilidad sísmica, muros cortantes/estructurales de hormigón armado

\section{ABSTRACT}

Reinforced concrete shear or structural walls are considered as effective lateral resisting systems in countries located in regions susceptible to earthquakes. However, it has been detected the necessity of more reliable procedures to determine the structural performance of these elements in order to prevent unexpected losses. This fact has been recognized from reported damage after the 
occurrence of recent strong earthquakes. In practice, fragility curves are used in seismic risk analysis because they are capable of quantifying the cumulative probability of failure related to an engineering design parameter. This paper details the fundamentals of the state-of-the-art associated with seismic fragility of selected cases where reinforced concrete structural walls are used. The aim is to promote more advanced and necessary studies in the region.

Keywords: Seismic fragility, reinforced concrete shear/structural walls

\section{INTRODUCTION}

Reinforced concrete shear/structural walls (RCSW) are used as effective seismic protection systems since they can provide an actual control of lateral displacements under service loads (Paulay \& Priestley, 1993). Additionally, when well-designed and detailed, this structural system can induce high levels of strength and ductility under ultimate loads (Chai \& Elayer, 1999).

Damage on RCSW buildings captured after recent earthquakes demonstrated that the lack of ductility led to catastrophic consequences. Unfortunately, even when the minimum code requirements where applied through the design and construction stages, some buildings reported severe economic losses. This fact highlighted the necessity of promoting more consistent analysis methods (Avalos, Haro, \& Caiza, 2016).

Formerly, reliability-based design for lateral loads has become a common practice to characterize seismic demand and seismic capacity of any kind of structure. On this subject, seismic fragility functions were introduced to determine the probability that geotechnical, structural and nonstructural systems reach or exceed a limit state when subjected to an earthquake of specified intensity (Kafali \& Grigoriu, 2004).

A precise method to implement fragility functions for RCSW has not been defined because of the great degree of uncertainty that is involved in the entire procedure when specifying ground motion characteristics, analytical models, material properties, or damage states (Papailia, 2011), suggesting further investigation that could be advanced in the region. For this reason, the following sections present four selected cases where seismic fragility analyzes are conducted on RCSW systems that could be considered as a reference for future studies.

\section{FRAGILITY CURVES FOR MULTISTORY RESIDENTIAL BUILDINGS}

One general concern regarding RCSW in terms of risk assessment analysis is the reliability of fragility curves originated from typical building properties and ground motions selected from local realities. In this context, Mieses, López, \& Saffar (2007) created fragility curves for medium rise residential buildings 
composed by structural walls in both directions, located in Puerto Rico, country characterized for a high seismicity. Past earthquakes records of the region were not available, therefore three earthquake records widely used for researchers (Imperial Valley, Northridge and San Salvador earthquakes) and two artificial seismic signals based on the geotectonic properties of Puerto Rico were used.

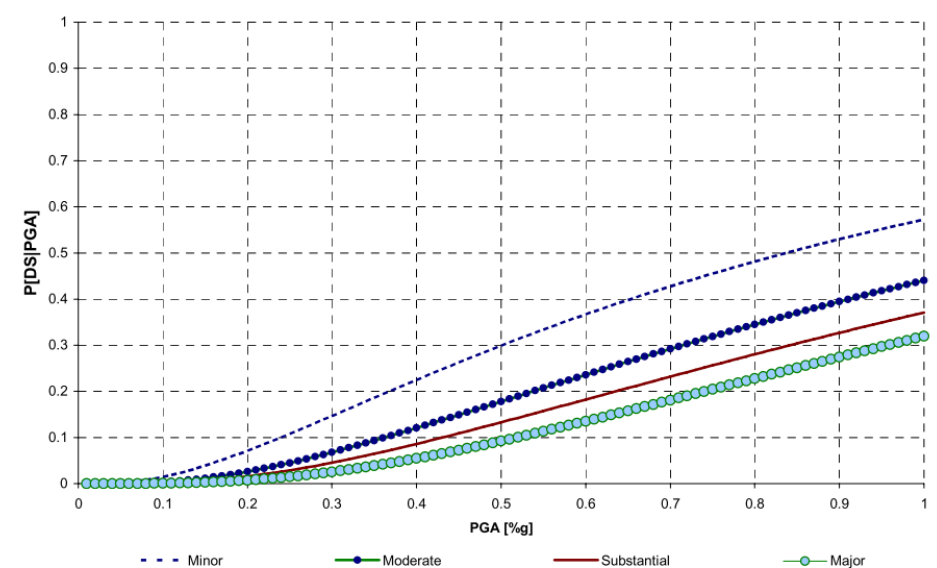

(a)

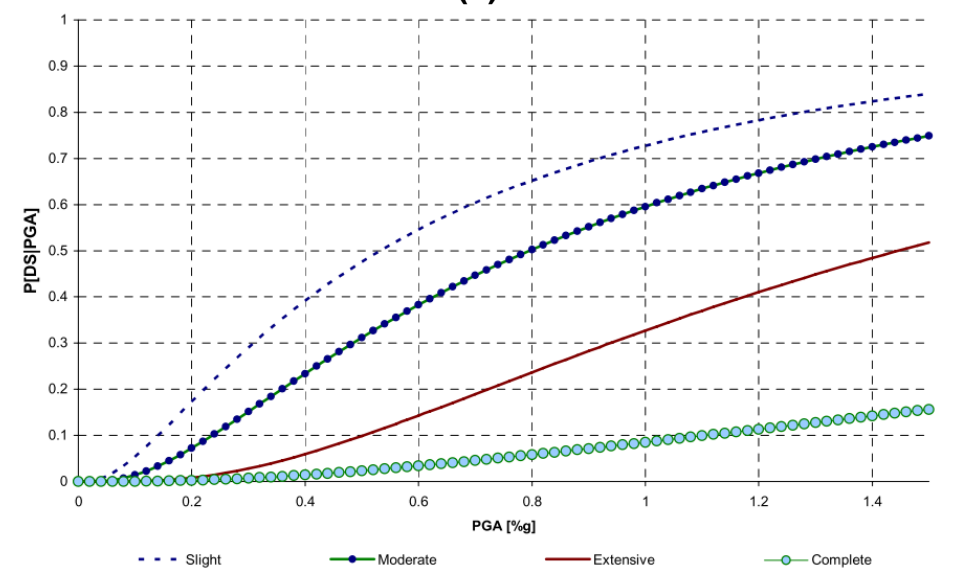

(b)

Figure 1 Fragility curves for multistory residential RCSW buildings. (a) Algan. (b) HAZUS. (Mieses et al., 2007)

The analysis of the buildings considered a nonlinear dynamic time history method. The nonlinear behavior of the structural walls was evaluated by flexure and shear contribution. The expected damage of the 26 different 2-D models was determined using Algan (1982) formulation and HAZUS (FEMA, 2003a) drift limits. Algan's formulation estimates the damage index from the difference between the drift index angle for the considered story and the joint rotation at the bottom floor level. This study took into account four damage states from the detailed formulation: Minor, Moderate, Substantial and Major. HAZUS contemplates the 
following limit states for RCSW: Slight, Moderate, Extensive and Complete. These damage states are base on drift index for different design grades.

Four fragility curves were created as a function of the Peak Ground Acceleration (PGA), for each damage state. Lognormal functions were used to describe the probability of violating the limit states. The set of fragility curves as a function of PGA proposed for the considered population is plotted in Figure 1. A low probability of damage was identified for the multistory buildings when subjected to earthquake forces because of their appropriate structural behavior. Regarding the expected damage scenarios, it is concluded that HAZUS (FEMA, 2003a) limit states represent more realistic behaviors than what suggested by Algan (1982).

\section{$3 \quad$ FRAGILITY CURVES FOR PUBLIC SCHOOL BUILDINGS}

Hancilar et al. (2006) studied spectral displacement-based probabilistic structural fragility analysis of a standardized four story public school building located in Istanbul. Nonlinear time-history analyses were conducted for 107 real strong ground motion records taken within $0-50 \mathrm{Km}$ with magnitudes between 5.8 and 7.6. A three-dimensional finite element model was carried out in order to establish the structural response. The Intensity Measure (IM) was defined by the spectral displacement at the fundamental vibration of the building. The IM quantifies the influence of an earthquake on a structure. For the Engineering Demand Parameter (EDP), which accounts for the structural damage, the maximum inter-story drift ratio was considered.

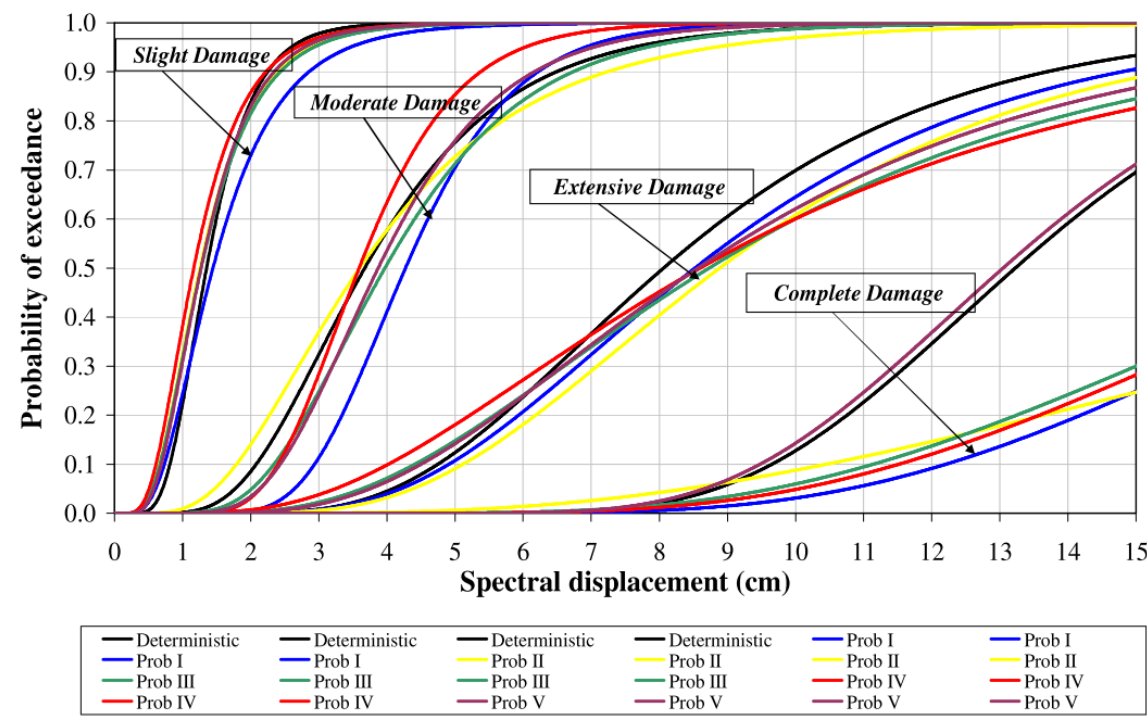

Figure 2 Damage Fragility curves for multistory residential RCSW buildings including. (Hancilar et al., 2006)

The main objective of this study was to determine the incidence of uncertainties associated with material properties, geometrical characteristics and the angle of the earthquake motion. A probabilistic method was followed in order to 
include all of these uncertainties and to determine which of them affects more the vulnerability of the structure. Monte Carlo simulation techniques were used to evaluate the fragility curves. Normal distributions were assumed for concrete density, span lengths, reinforcing steel strength and concrete compressive strength. The earthquake angle was uniformly distributed covering $360^{\circ}$, and the cross-sectional dimensions were uniformly distributed between bound values considered from in-situ measurements.

Six different damage levels were considered in the study where one deterministic case and five probabilistic cases were defined. Figure 2 shows the fragility curves for all analysis cases evaluated for four damage limits. The fragility curves showed that the highest influence was detected for uncertainties in span lengths, story heights and mass of the building. Additionally, the results were also compared with HAZUS (FEMA, 1999) damage states, where moderate, extensive and complete damage levels resulted lower than those contemplated in this study.

\section{FRAGILITY CURVES WHEN SOIL-STRUCTURE INTERACTION EFFECTS ARE CONSIDERED}

There have been described some uncertainties that influence the seismic performance of RCSW. However, in addition the behavior of structural walls depends on the nonlinear response of supporting soil-foundation system and the interaction between them. In order to take into account these parameters, Tang \& Zhang (2010) conducted a study to determine probabilistic seismic demand of RCSW including soil-structure interaction (SSI) effects. The structure considered for the analysis was a generic code-conforming slender seven story RCSW in western U.S. raised over a mat foundation. The inelastic spectral displacement $\left(S_{d i}\right)$ was used as the IM because it tends to be more effective than other IMs for first-mode dominated nonlinear structures. The probabilistic analysis was realized for fixed and flexible supports to visualize the impact of SSI effects. Nonlinear time history analyses were implemented for a total of 70 near-fault and 291 ordinary ground motion records. The peak inter-story drift, a random variable with dispersion $\varepsilon(I M)$ that follows a log-normal distribution, was taken as one of the EDPs. The linear and nonlinear foundation models were considered additionally as EDPs.

The damage states for mid-rise RCSW based on inter-story drift ratios included in the analysis are those established by HAZUS-MH MR4 (FEMA, 2003b); i.e., $L s=0.27 \%, 0.67 \%, 2.0 \%$ and $5.33 \%$ for slight, moderate, extensive and complete damage states, respectively. Accordingly, the fragility functions were deducted as follows:

$$
P(E D P \geq L s \mid I M)=1-\int_{0}^{L s} \frac{1}{\sqrt{2 \pi} \sigma_{\ln \varepsilon}} \exp \left(-\frac{(\ln x-\ln h(I M))^{2}}{2 \sigma_{\ln \varepsilon}^{2}}\right) d x
$$

where $L s$ is the damage level for a given $\mathrm{IM} ; \sigma_{\ln \varepsilon}$, is the standard deviation derived in Tang \& Zhang (2010) as a function of the foundation case (e.g., for a fixed-base foundation $\left.\sigma_{\ln \varepsilon}=0.1069\right)$; and, $h(I M)$ denotes the expected value of EDP for the given IM. 
The results demonstrated that the SSI effects have a propensity to decrease the seismic demands on structural walls, which implies a reduction in the probability of exceeding certain damage limit. Additionally, it was detected a significant difference between the linear and nonlinear foundation fragility functions and it is suggested further investigation to determine whether or not to include the foundation damage in the overall system damage.

\section{FRAGILITY CURVES OF SHORT PERIOD RCSW FROM EXPERIMENTAL DATA}

As well as field observation has been important for assessment of fragility, laboratory tests can also provide objective information. In this context, Sasani, Kiureghian, \& Bertero, (2002) used experimental data and the Bayesian technique to generate probabilistic capacity and demand models for RCSW with a medium to large aspect ratio. The Bayesian method is an effective tool capable of accounting for uncertainties related to imperfections in numerical models, measure inaccuracies, finite size of observed samples and subjective information derived from engineering criteria.

The seismic capacity was evaluated by flexural and shear failure. The demand probabilistic model was developed by nonlinear dynamic analyses of multi degree of freedom (MDOF) and single degree of freedom (SDOF) systems. The concept of significant peak ground acceleration (SPGA) was introduced as a more reliable measure of the ground motion intensity for short-period structures at the life safety limit state, which was selected for this specific study.

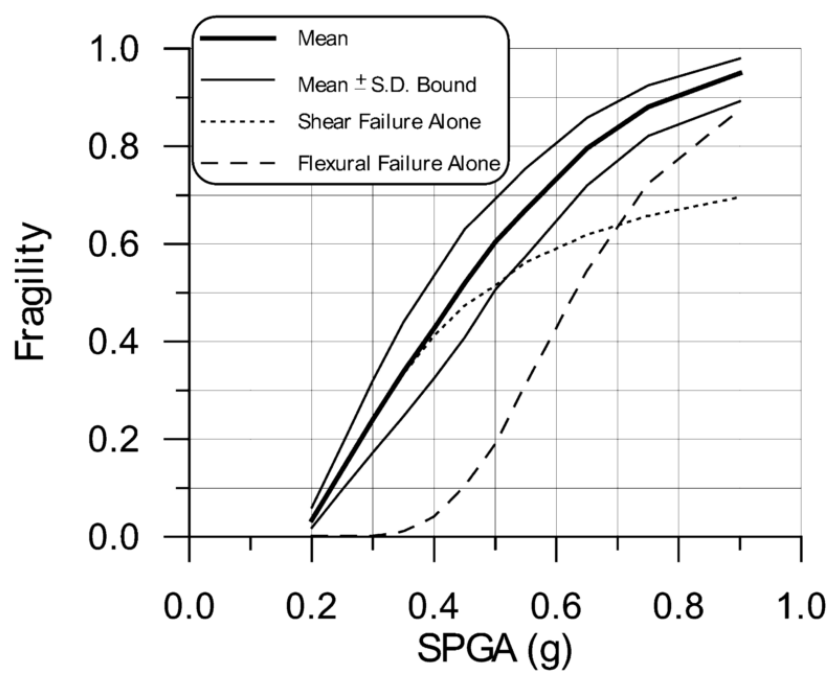

Figure 3 Damage Fragility curves for a sample wall.

(Sasani et al., 2002) 
Figure 3 presents fragility curves for the sample-investigated wall where the effects of material variabilities are included. These results were obtained from First Order Reliability Methods (FORM). The formulations derived in this study to estimate fragility curves for RCSW, demonstrated to consider properly intrinsic and epistemic uncertainties for structural walls with short periods and with medium to large aspect ratios.

\section{CONCLUSIONS}

It is essential to be aware of the limitations and sensitivities of different analysis methods and the significance of authenticating these methods against experimental data. Laboratory tests and field observations have produced treasured data, which, together with insights that are gained from the various correlation analyses, serve as confident resource for seismic fragility estimates of RCSW structures.

Four noteworthy cases were chosen to represent the fundamentals on the state-of-the-art in seismic fragility studies for RCSW. It is observed that further research is required to accurately predict seismic demands and seismic capacities of RCSW under the framework of performance-based design and seismic assessment.

\section{ACKNOWLEDGMENTS}

The research described in this paper is supported by the Secretaría de Educación Superior Ciencia y Tecnología e Innovación (SENESCYT) and the Universidad de las Fuerzas Armadas ESPE. This review is part of the PhD studies conducted at the North Carolina State University, Raleigh.

\section{REFERENCES}

Algan, B. B. (1982). Drift and Damage Considerations in Earthquake-Resistant Design of Reinforced Concrete Buildings. University of Illinois at UrbanaChampaign.

Avalos, C., Haro, A. G., \& Caiza, P. (2016). Main Reasons of Structural Wall Collapse in Chile 2010 and New Zealand 2011 - Implications For Ecuador. The Open Civil Engineering Journal, 10, 3-16.

Chai, Y. H., \& Elayer, D. T. (1999). Lateral stability of reinforced concrete columns under axial reversed cyclic tension and compression. ACI Structural Journal, 96(96), 780-789.

FEMA. (1999). HAZUS 99 (SR2). Technical Manual. Washington, D.C.

FEMA. (2003a). HAZUS-MH MR1. Earthquake Model. Advanced Engineering Building Module. Washington, D.C.

FEMA. (2003b). HAZUS-MH MR4. Earthquake Model. Thechnical Manual. Washington, D.C.

Hancilar, U., Durukal, E., Franco, G., Erdik, M., Deodatis, G., \& Smyth, A. (2006). Spectral Displacement-Based Probabilistic Structural Fragility Analysis of a Standardized Public School Building in Istanbul, 1-9.

Kafali, C., \& Grigoriu, M. (2004). Seismic Fragility Analysis. In 9th ASCE Specialty Conference on Probabilistic Mechanics and Structural Reliability (pp. 1-6). 
Albuquerque, New Mexico.

Mieses, L. A., López, R. R., \& Saffar, A. (2007). Development of fragility curves for medium rise reinforced concrete shear wall residential buildings in Puerto Rico. Mecánica Computacional Vol XXVI, 2712-2727.

Papailia, A. (2011). Seismic fragility curves for reinforced concrete buildings. University of Patras.

Sasani, M., Kiureghian, A. Der, \& Bertero, V. V. (2002). Seismic fragility of short period reinforced concrete structural walls undernear-source ground motions. Structural Safety, 24, 123-138.

T. Paulay and M. J. N. Priestley. (1993). Stability of Ductile Structural walls. ACl Structural Journal, 90, 385-392.

Tang, Y., \& Zhang, J. (2010). Probabilistic seismic demand analysis of a slender RC shear wall considering soil - structure interaction effects. 19th Analysis \& Computation Specialty Conference (c) 2010 ASCE, 19(1), 37-47. http://doi.org/10.1016/j.engstruct.2010.10.011 